\title{
Exacerbation of rheumatoid arthritis in patients treated with methotrexate after administration of folinic acid
}

\author{
David A Joyce, Robert K Will, David M Hoffman, Beverley Laing, Steve J Blackbourn
}

\begin{abstract}
A double blind, placebo controlled trial examined the effects of folinic acid on the efficacy and toxicity of methotrexate in 27 patients with rheumatoid arthritis. Clinical and laboratory indices of disease activity worsened significantly in the 13 patients treated with folinic acid after four weeks of treatment, but not in the 14 patients treated with placebo. Exacerbation of rheumatoid arthritis led to withdrawal of the test drug in seven of the patients treated with folinic acid but in none of those treated with placebo. It is concluded that excerbation of rheumatoid arthritis is likely when folinic acid is given shortly after the weekly dose of methotrexate.
\end{abstract}

Gastrointestinal and bone marrow toxicity often complicate the treatment of rheumatoid arthritis with methotrexate. These are caused by impaired cell replication, which is largely due to depletion of intracellular tetrahydrofolate. ${ }^{1}$ Replenishing intracellular tetrahydrofolate stores by oral administration of folinic acid (leucovorin: 5formyltetrahydrofolate), therefore, may limit methotrexate toxicity. This strategy will succeed if cells of the gut and bone marrow are more responsive to folinic acid replacement than methotrexate 'target' cells. The optimum dose and timing for administration of folinic acid to exploit a differential sensitivity have not been established. We now report the effects of early administration of $15 \mathrm{mg}$ folinic acid on the efficacy and toxicity of methotrexate in patients with rheumatoid arthritis.

Department of Pharmacology, University of Western Australia, Nedlands,

Western Australia, Australia, 6009

D A Joyce

Department of

Rheumatic Diseases, Royal Perth

(Rehabilitation) Hospital,

Shenton Park,

Western Australia, 6008,

R K Will

D M Hoffman

B Laing

Pharmacy Department, Royal Perth Hospital,

Perth, 6000

S J Blackbourn

Correspondence to:

Dr Joyce.

Accepted for publication

3 May 1991

\section{Materials and methods}

Twenty seven patients with rheumatoid arthritis $^{2}$ who had been treated with oral methotrexate for over three months were randomly allocated, double blind, to folinic acid or placebo treatment groups. Patients received either a single oral dose of $15 \mathrm{mg}$ folinic acid or an indistinguishable placebo in tablet form (Lederle Laboratories) at two hours after the weekly methotrexate dose.

Patients were assessed by a doctor and a metrologist at two weeks before randomisation, at the time of randomisation, and at four, eight, and 12 weeks. Ritchie index, joint pain (visual analogue scale), duration of morning stiffness, and the patient's global assessment of the status of their joints (visual analogue scale) were recorded at each visit. Results of clinical assessments at two weeks before and at the time of randomisation were averaged to obtain the baseline value for each measure of disease activity. Patients were assessed for clinical toxicity at each visit. Blood cell counts, erythrocyte sedimentation rate (Westergren), and liver function tests were done at randomisation and at four, eight, and 12 weeks. Chest radiographs and pulmonary function tests were obtained at randomisation and at 12 weeks. Results are expressed as mean (SEM).

\section{Results}

The group treated with folinic acid (13 patients) and the placebo group (14 patients) were of comparable mean age $59 \cdot 8(3.6)$ and $62 \cdot 8(3 \cdot 5)$ years respectively), sex distribution, rheumatoid factor status, and disease activity at entry (figure). The weekly doses of methotrexate were $7.9(0.6) \mathrm{mg}$ in the group treated with folinic
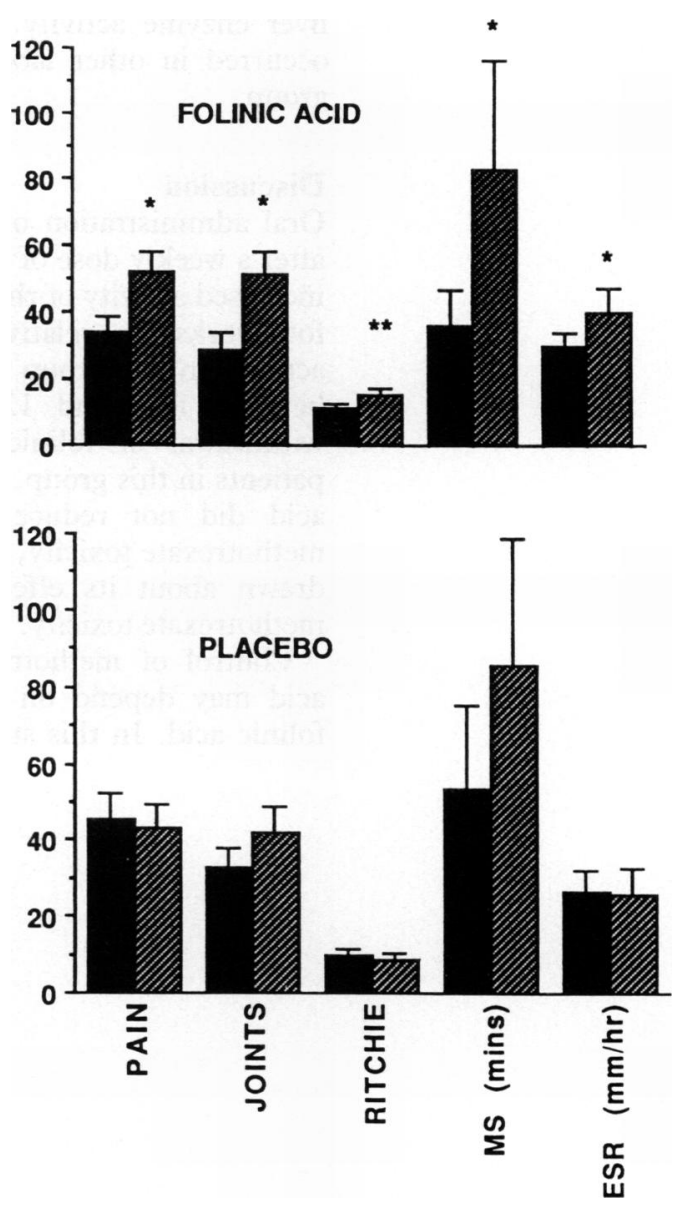

Pain, joint score, Ritchie index, duration of morning stiffness $(M S)$, and erythrocyte sedimentation rate $(E S R)$ in the groups treated with folinic acid (upper panel) and placebo (lower panel) at entry (black bars) and at four weeks (hatched bars). Means (SEM) are shown. Where values differ significantly from entry values the levels of significance are shown $\left({ }^{*} \mathrm{p}<0.05 ;{ }^{* *}=\mathrm{p}<0.01\right)$. 
acid and $8.2(0.5) \mathrm{mg}$ in the group treated with placebo. No patient was receiving any other disease modifying agent or high dose steroids.

When compared with baseline the group treated with folinic acid showed increases in Ritchie index $(p<0.01)$, pain $(p<0.05)$, global joint score $(p<0.05)$, duration of morning stiffness $(p<0.05)$, and erythrocyte sedimentation rate $(p<0.05)$ at four weeks (Wilcoxon matched pairs test; figure). Return towards baseline level was seen for each of these indices at eight and 12 weeks in this group (results not shown). There was no significant change in any measure of disease activity in the group treated with placebo. No patient from the placebo group was withdrawn, whereas three patients from the treatment group were withdrawn before four weeks and another four were withdrawn between four and 11 weeks $(p=0.002$; Fisher's exact test).

The incidences of methotrexate toxicity and methotrexate withdrawal did not differ significantly between the groups. Probable methotrexate toxicity led to withdrawal of the drug in three patients in the group treated with folinic acid (two with nausea and one with corneal herpes simplex infection) and one patient in the placebo group (mouth ulceration). One additional patient in each group experienced selflimiting mouth ulceration and one patient in the placebo group experienced a small increase in liver enzyme activity. No significant changes occurred in other laboratory results in either group.

\section{Discussion}

Oral administration of folinic acid, two hours after a weekly dose of methotrexate, resulted in increased activity of rheumatoid arthritis within four weeks. The relative improvement in disease activity in the group treated with folinic acid between four and 12 weeks coincided with withdrawal of folinic acid in seven of the patients in this group. Administration of folinic acid did not reduce the total incidence of methotrexate toxicity, but no conclusion can be drawn about its effect on specific forms of methotrexate toxicity.

Control of methotrexate toxicity by folinic acid may depend on the timing and dose of folinic acid. In this study the folinic acid dose was about twice the methotrexate dose (in milligrams) and was given at two hours. Tishler et al used three times the methotrexate dose, beginning at four to six hours, ${ }^{3}$ but exacerbation of rheumatoid arthritis was seen in this study also. A smaller relative dose of folinic acid (1 mg/mg methotrexate) given at four hours did not lead to exacerbation and was associated with a trend towards less gastrointestinal upset and stomatis. ${ }^{4}$ There are case reports of successful management of bone marrow toxicity and stomatitis with folinic acid given between 12 and 48 hours after methotrexate $(30 \mathrm{mg}$ folinic acid, methotrexate dosage not stated $)^{5}$ and at 14 to 16 hours ( $5 \mathrm{mg}$ folinic acid, $5 \mathrm{mg}$ methotrexate) ${ }^{6}$ No exacerbations of arthritis occurred. However, $20 \mathrm{mg}$ folinic acid, given at three to four days after methotrexate (mean dose 18.5 $\mathrm{mg}$ ) was no more effective than placebo in controlling nausea. ${ }^{7}$ These studies suggest that early administration of a large dose of folinic acid (within six hours of methotrexate) leads to exacerbation of rheumatoid arthritis and that late administration three to four days after methotrexate is ineffective.

Further clinical studies are necessary to determine whether the judicious use of folinic acid can improve the safety and efficacy of methotrexate. Available data suggest that dosing at between 12 and 48 hours after methotrexate offers the greatest promise. The optimum dose has yet to be determined.

1 Goldman I D, Matherly L H. Biochemical factors in the selectivity of leucovorin rescue: selective inhibition of leucovin reactivation of dihydrofolate reductase and leumethotrexate and dihydrofolate polyglutamates. NCI Monogr 1987; 74: 17-26.

2 Arnett F C, Edworthy S M, Bloch D A, et al. The American Rheumatism Association 1987 revised criteria for the classification of rheumatoid arthritis. Arthritis Rheum 1988; 31 : 315-24.

3 Tishler M Caspi D, Fishel B, Yaron M. The effect of leukovorin (folinic acid) on methotrexate therapy in rheumatoid arthritis patients. Arthritis Rheum 1988; 31: 906-8.

4 Buckley L M, Cooper S M, Vacek P M. The use of leucovorin after low dose methotrexate in patients with rheumatoid after low dose methotrexate in patients with rhe
arthritis. Arthritis Rheum 1988; 31 (suppl 4): S115.

5 Baker R I, Manoharan A. Cytopenias induced by methotrexate in rheumatoid arthritis. Aust NZ F Med 1989; 19: 747.

6 Polk J R. Beneficial effect of leucovorin after methotrexate in rheumatoid arthritis: a case report. Arthritis Rheum 1988, 31: $1587-8$.

7 Hanrahan P S, Russell A S. Concurrent use of folinic acid and methotrexate in rheumatoid arthritis. $\mathcal{f}$ Rheumatol 1988 15: 1078-80. 